\title{
Escola democrática e de direitos inclusivos em meio aos desafios Amazônicos
}

Cátia de Lemos

Secretaria Municipal de Educação de Manaus (Brasil)

Maria Almerinda de Souza Matos

Universidade Federal do Amazonas (Brasil)

\section{Resumo}

A pesquisa surge num momento de profundo questionamento sobre as políticas educacionais e sua efetivação. Teve como objetivo analisar os desafios identificados para tornar a escola pública, mais democrática, participativa, emancipatória e inclusiva no cenário amazônico. Para cumprir o objetivo proposto, utilizou-se a análise documental da legislação brasileira e local. Estudos dialéticos perpassam todo o texto e o aporte teórico foi baseado nas contribuições de Cury (2002), Mészarós (2005), Gadotti (2006) e Matos (2014). Realizou-se entrevistas semiestruturadas com a participação de 26 agentes educacionais. Portanto, a pesquisa convida o leitor a aprofundar o debate em âmbito nacional quando aponta para desafios educacionais vivenciados pelos povos amazônicos, como formação de professores, escassez de materiais, cooperação técnica, equipe multiprofissional, acessibilidade e família. Contudo, almeja-se que a escola democrática não sirva somente para visibilizar, mas, proporcionar oportunidades educacionais para todos os educandos, com ou sem deficiência, respeitando a diversidade humana. Palavras-chave: Escola democrática. Inclusão. Políticas educacionais. Desafios amazônicos.

\section{Democratic and inclusive rights school in the midst of the Amazonian challenges}

\begin{abstract}
The research arises at a moment of profound questioning on educational policies and their effectiveness. It aimed to analyze the challenges identified to make the public school more democratic, participatory, emancipating and inclusive in the Amazonian scenario. To accomplish the proposed objective, the documental and Brazilian local legislation analysis were applied. Dialectical studies go throughout the whole text and the theoretical input was based on the contributions of Cury (2002), Mészarós (2005), Gadotti (2006) and Matos (2014). Semi-structured interviews were carried out with the participation of 26 educational agents. Therefore, the research invites the reader to deepen the debate at the national level, when it points out educational challenges experienced by the Amazonian peoples, such as teacher training, scarcity of materials, technical cooperation, multi-professional team, accessibility and family. However, the aim is that democratic school will not only serves to make visible, but also to provide educational opportunities for all students, whether with or without disabilities, respecting human diversity.

Keywords: Democratic school. Inclusion. Educational policies. Amazonian challenges.
\end{abstract}




\section{Escuela de derechos democráticos e inclusivos en medio de los desafíos Amazónicos}

\section{Resumen}

La investigación surge en un momento de profundo cuestionamiento sobre las políticas educativas y su efectividad. Su objetivo fue analizar los desafíos identificados para hacer la escuela pública más democrática, participativa, emancipadora e inclusiva en el escenario amazónico. Para cumplir con el objetivo propuesto, se utilizó el análisis de documentos de la legislación brasileña y local. Los estudios dialécticos recorren todo el texto y el aporte teórico se basó en las contribuciones de Cury (2002), Mészarós (2005), Gadotti (2006) y Matos (2014). Se realizaron entrevistas semiestructuradas con la participación de 26 agentes educativos. Por lo tanto, la investigación invita al lector a profundizar el debate a nivel nacional, cuando señala los desafíos educativos vividos por los pueblos amazónicos, tales como formación docente, la escasez de materiales, cooperación técnica, equipo multiprofesional, accesibilidad y familia. Sin embargo, se espera que la escuela democrática no solo sirva para hacer visible, pero que también ofrezca oportunidades educativas a todos los estudiantes, con o sin discapacidad, respetando la diversidad humana.

Palabras clave: Escuela democrática. Inclusión. Políticas educativas. Desafíos Amazónicos.

\section{Introdução}

As constantes evoluções vivenciadas na sociedade contemporânea exigem um posicionamento de educandos, educadores, gestores municipais, dirigentes escolares e pesquisadores comprometidos com as demandas sociais no que se refere às políticas públicas educacionais brasileiras.

No confronto de debates e disputas históricas entre o poder econômico que influencia diretamente as decisões educacionais no Brasil e a resistência combativa pela efetivação de políticas educacionais mais justas e solidárias, possivelmente, o conhecimento seja um expressivo argumento para as mudanças de atitudes e comportamentos. Com esse entendimento, o ato de conhecer assume aqui um sentido de luta pelos direitos e deveres, proporcionando o poder de articular negociações claras rumo aos anseios por melhores condições de vida.

Nesse sentido, uma questão central se apresenta: quais mudanças seriam necessárias nas políticas públicas para impulsionar a educação no processo de socialização dos conhecimentos rumo a uma escola pública mais democrática, inclusiva e emancipatória na contextura amazônica? 
artigo, que discorre acerca dessa inquietação, é um recorte dos resultados da pesquisa de doutorado em Educação intitulada: A Implementação das Políticas Públicas Educacionais de Inclusão nos Planos Municipais de Educação dos 62 Municípios do Amazonas ${ }^{1}$ - sob o parecer consubstanciado do CEP: 3.016.627-CAAE-2229018.1.0000.5020/UFAM/AM.

artigo divide a temática em dois aspectos:

- No primeiro, busca discutir alguns pontos sobre a Educação inclusiva no contexto amazônico assumindo um caráter crítico-analítico preliminar no que se refere aos passos e descompassos presentes em trechos da Lei de Diretrizes e Bases da Educação Nacional - LDBEN 9.394/1996. Decreto $6.571 / 2008$ que dispõe sobre o atendimento educacional especializado, Decreto $7.611 / 2011$ que substitui o Decreto 6.571/2008, Plano Nacional de Educação - PNE (2014/2024), Plano Estadual de Educação do Amazonas - PEE/AM (2015/2025) e Planos Municipais de Educação - PME's de alguns municípios elencados para a pesquisa previstos para vigorarem até 2025, frente aos desafios dessa região tão diversa, adversa, complexa e heterogênea.

- No segundo aspecto, visa abordar algumas reflexões sobre uma escola pública democrática que possa atender às especificidades amazônicas em uma perspectiva participativa, emancipatória e inclusiva. Permeia esse debate, 6 desafios educacionais identificados pela pesquisa, vivenciados pelos educandos e educadores com ou sem deficiência, que muitas vezes ainda se encontram à margem dos processos educacionais no longínquo cenário das florestas e das águas.

Também importa salientar que, dos 62 municípios inicialmente propostos pela pesquisa, foi possível investigar 18 Planos Municipais de Educação (PME's) e entrevistar 16 Secretários Municipais de Educação, 6 presidentes de APMC's e 4 coordenadores da Secretaria de Estado de Educação e Desporto - SEDUC/AM nos municípios. Foram escolhidos 2 municípios por "calha²" de rio, como se apresentam a seguir. Tabela 1

Amostra do estudo por calha de rio 


\section{Tabela 1}

Amostra do estudo por calha de rio

\begin{tabular}{|c|c|}
\hline Calhas & Municípios \\
\hline \multirow{2}{*}{ Alto Solimões } & Atalaia do Norte \\
\cline { 2 - 2 } Médio Solimões & Tonantins \\
\cline { 2 - 2 } & Juruá \\
\hline \multirow{2}{*}{ Purus } & Tefé \\
\cline { 2 - 2 } & Boca do Acre \\
\hline \multirow{2}{*}{ Juruá } & Pauini \\
\cline { 2 - 2 } & Carauari \\
\hline \multirow{2}{*}{ Madeira } & Morbarati \\
\cline { 2 - 2 } & Manicoré \\
\hline \multirow{2}{*}{ Alto Rio Negro } & São Gabriel da Cachoeira \\
\cline { 2 - 2 } & Santa lsabel do Rio Negro \\
\hline \multirow{2}{*}{ Rio Negro/Solimões } & Caapiranga \\
\cline { 2 - 2 } & Manaus \\
\hline \multirow{2}{*}{ Baixo Amazonas } & Parintins \\
\cline { 2 - 2 } & São Sebastião do Uatumã \\
\hline \multirow{2}{*}{ Médio Amazonas } & Itapiranga \\
\cline { 2 - 2 } & Silves \\
\hline
\end{tabular}

Quadro elaborado por Lemos (2019).

Apesar da divisão dos municípios, realizada pelo MEC, ocorrer por polos, neste trabalho optou-se por utilizar a divisão por calhas, na tentativa de valorizar a regionalidade local. Os critérios para tal escolha serão melhor detalhados na seção intitulada: Metodologia.

Para garantir o sigilo de informações concedidas pelos participantes, os municípios pesquisados receberam codinomes de peixes conhecidos na região amazônica e que serão assim citados no artigo.

Desse modo, espera-se que o artigo venha suscitar novos olhares sobre as políticas públicas educacionais e, longe de tentar desenhar um quadro único, fortaleça o debate sobre os rumos percorridos pela Educação brasileira, 
regional e local para a construção de uma escola pública que oportunize a todos se tornarem protagonistas das próprias histórias, com direitos fundamentais atendidos e respeitados por todos os setores da sociedade.

\section{Metodologia}

Compreendendo a Educação como um dos instrumentos de luta e resistência na vida de milhares de pessoas com deficiência presentes/ausentes do processo educacional dos 18 municípios investigados no Amazonas, o estudo assumiu um enfoque dialético, baseando-se nos estudos de Sânchez Gamboa (1998). O autor afirma que a dialética é uma teoria crítica que discute a realidade, não somente na produção do conhecimento humano, mas na ação dos homens em uma busca constante pela transformação dessa dada realidade social.

Desse modo, o homem, fruto da realidade histórica, é dotado de inteligência, pensamento crítico e ideias que o diferenciam dos demais animais, estabelecendo com o mundo uma relação de responsabilidade e compromisso perante a vida de todos os seres humanos, pois, o método precisa estar sempre vinculado ao pensar e ao agir dos homens no mundo em que vivem.

Seguindo essa concepção de crítica à realidade, objetivou-se analisar as políticas públicas que norteiam o objeto do estudo (planos municipais de Educação no que se referem à implementação da meta 4 do PNE [2014/2024] no Amazonas). A inquietação do estudo foi descobrir se os planos municipais de Educação obedecem a parâmetros de mudanças sócio-históricas ou continuam a serviço da manutenção das relações de poder vivenciadas pelas sociedades capitalistas por meio de políticas assistencialistas e de cunho caritativo.

A opção pela escolha da divisão dos municípios em 9 calhas de rios também se refletiu na amostragem do estudo, na qual procuramos analisar os planos municipais de Educação de dois municípios por calha. Na seleção, um dos municípios apresentou um maior Índice de Desenvolvimento da Educação Básica - IDEB e um outro, um índice menor. Avaliamos como essa diferença poderia ou não influenciar na criação de salas de recursos multifuncionais - SRM's para um devido atendimento ao segmento dos educandos com deficiência. 
Como este artigo é um recorte de uma tese de doutorado, analisou-se somente uma das 7 categorias originadas pela pesquisa: Os desafios que dificultam a implementação da universalização do ensino para os educandos de 4 a 17 anos que apresentam uma condição de deficiência.

\section{Políticas públicas educacionais: pontos, contrapontos, desafios e rotas de chegada}

Vivencia-se um momento em que a Educação é colocada à prova e onde a emergência por novos percursos políticos, econômicos, sociais, tecnológicos, científicos, ideológicos, culturais e ambientais vão interferir diretamente no desenho educacional brasileiro para as gerações vindouras. Nesse cenário, por um lado permeado pelas complexidades da conjuntura mundial e, pelo outro, por diversas realidades regionais, há que nos situarmos de que lugar pode-se refletir acerca das mudanças necessárias para que as políticas públicas educacionais se constituam em ações afirmativas.

Embora os processos educacionais ofereçam possibilidades de mudanças importantes nos contextos políticos, educacionais, econômicos e sociais, discorda Mészarós (2005) quando afirma que a Educação, por si só, não pode transformar a sociedade rumo à emancipação social, enquanto as reformas educacionais não compreenderem a universalização do trabalho como dimensão indissociável da Educação.

Indiscutivelmente, pensar em universalizar o trabalho em um país que, segundo dados do Instituto Brasileiro de Geografia e Estatística - IBGE (2015), finalizou o ano com 1,8 milhões de desempregados - número que aumentou de maneira exorbitante para 12,2 milhões de pessoas sem emprego, conforme o mesmo instituto (2018) - requer de todos os educadores uma reflexão crítica sobre as veladas intenções dos discursos reformistas escamoteados na legislação educacional brasileira. Ao negar uma Educação de qualidade, discutida aqui como um processo sócio-histórico, essa legislação também nega às populações excluídas a oportunidade de acesso ao mundo do trabalho, como destacam Vieira (2001) e Cury (2002).

Contribuindo com essa análise, em um momento de profunda assimetria entre os donos do capital e a força de trabalho, o Estado atua como regulador da manutenção das relações capitalistas, legitimando e defendendo 
os interesses da ideologia dominante, como afirmam Hofling (200 1), Guareschi (2003), Mészarós (2005), entre outros.

Na sociedade globalizada e globalizante, o educador é impelido a difundir e socializar as informações, o conhecimento, a inovação e as novas tecnologias para aprender e ensinar. No entanto, chama a atenção Costa (2006) para que não se globalize também o poder do capital, atropelando as especificidades locais, ao imprimir nos sujeitos uma padronização massificante.

Desse modo, explica ainda Costa (2006) que em um mercado de consumo global, cria-se um clima de competição e disputas acirradas, onde a regra do jogo é somente lucrar, sem a preocupação com as questões éticas e morais.

Estudos de Gadotti e Romão (2004), Mészarós (2005) e Sousa Júnior (2010) provocam uma séria reflexão quando afirmam que, mesmo que a escola desempenhe um papel de aparelho ideológico do Estado, poderia ao menos educar para a socialização dos conhecimentos, oportunizando para que mais pessoas tivessem acesso às informações, ao ensino, ao trabalho, ao lazer, enfim, aos demais direitos sociais.

Uma possibilidade para mudanças de atitude seria a organização social em um esforço coletivo entre os órgãos governamentais e a sociedade civil para esclarecer toda a população que a plena participação dos educandos com deficiência na escola não é um privilégio, fruto da bondade política, ou um benefício, mas sim um direito adquirido, presente em inúmeras legislações das quais países como o Brasil são signatários.

Pesquisadores como Saviani (201 1), Tavares e Souza (2013) e Matos (2014), estabelecem uma análise profunda das demandas advindas do Plano Nacional de Educação - PNE (2014/2024), pois, percebem a Educação especial não como filantropia ou assistencialismo, mas, como um direito adquirido, que precisa ser concebido, assegurado e respeitado na integralidade.

Na vida prática, como se referem Vieira (2001) e Cury (2002), as transformações sociais não se fizeram e não se fazem se não houver uma mobilização popular por parte dos trabalhadores e demais atores sociais.

A esse respeito, afirma Batista (2015), as iniciativas de proteger os direitos conquistados pelas pessoas com deficiência começaram a assumir um novo caráter no Brasil a partir dos anos 1960 com o surgimento de 
movimentos em prol dos direitos deste segmento até então excluído e apartado das oportunidades.

No Estado do Amazonas, esses movimentos, surgidos na década de 1980, reunidos em associações, Conselhos Municipais, Conselho Estadual de luta pelos direitos das pessoas com deficiência e demais fóruns, continuaram a se fortalecer nos setores da Educação, trabalho, saúde, seguridade social, acessibilidade, lazer, moradia, entre outros, monitorando e avaliando o cumprimento das políticas públicas existentes. Pagliuca, Mariano, Oliveira, Oliveira, França e Almeida relembram que:

Embora o Brasil tenha sido um dos países mais inclusivos das Américas por coordenar medidas administrativas, legislativas, judiciais e políticas públicas, o movimento social das $\mathrm{PcD}^{3}$ demanda ações práticas de implementação dessas políticas, a fim de atingir a totalidade desse segmento, pois os avanços não são possíveis sem a ałuação engajada e militante da sociedade civil organizada (PAGIIUCA; MARIANO; OLIVEIRA; OLIVEIRA; FRANCCA; ALMEIDA, 2015, p. 499).

Segundo os autores, a sociedade não pode se eximir do papel fiscalizador das políticas públicas para que os desmandos governamentais não prejudiquem ainda mais a população.

Analisando os dados do PME/Manaus/AM (2015/2025, p. 67), "[...] o município de Manaus possui 82,1\% da população de 4 a 17 anos com deficiência que frequenta a escola, logo necessita incluir os 17,9\% restantes que não estão recebendo o Atendimento Educacional Especializado - AEE". A partir desse dado, é inegável o progresso das políticas afirmativas que objetivam promover a Educação em uma perspectiva inclusiva no município de Manaus/AM, mas, subentende-se que 17,9\% dos estudantes com deficiência ainda não tiveram acesso nem à matrícula no sistema educacional nem aos atendimentos que a Legislação assegura. $\bigcirc$ fato é exemplificado no PME/Manaus/AM (2015/2025, p. 67) com "[...] o Atendimento Educacional Especializado - AEE", cabendo ressaltar que a Educação Inclusiva não se reduz somente a esse serviço.

Com esse caráter, o PEE/AM (2015/2025) afirma, na estratégia 4.3, que, para atingir a Meta 4 do PNE (2014/2024), dever-se-á: 
Implantar e implementar, na vigência deste PEE, Salas de Recursos Multifuncionais em 100\% dos municípios do Estado, contemplando Escolas urbanas, do campo, indígenas e de comunidades quilombolas, garantindo a formação específica aos professores para atuação no Atendimento Educacional Especializado (BRASIL, 2014).

De acordo com essa estratégia, a Educação do Amazonas se vê frente a grandes desafios não apenas na formação, informação e transformação da concepção dos educadores a respeito da inclusão educacional, mas, principalmente, na construção da identidade cultural de cada educador a partir das diversas realidades em que estão inseridos.

Um segundo desafio é o enfrentamento das dificuldades de acesso à maior parte dos municípios do Estado. Trata-se aqui de municípios que contam apenas com transportes por via fluvial, distantes, em alguns casos, a dias de viagem, além das dificuldades de acesso às escolas do campo e às áreas ribeirinhas mais afastadas.

Outro fator preponderante a ser levado em consideração são os calendários escolares específicos que, muitas vezes, permitem que os educandos frequentem 6 meses de aulas dependendo da época das cheias ou vazantes dos rios. Tal realidade muda de acordo com as variações climáticas que ocorrem ano após ano.

Um aspecto a ser observado é que grande parte das escolas, apesar dos discursos falaciosos e midiáticos do poder público, não reúnem condições estruturais para receber os equipamentos destinados às salas de recursos multifuncionais, enviados pelo Ministério da Educação.

Ainda de acordo com o Plano Nacional de Educação - PNE (2014/2024), mesmo que os estados e municípios criem os próprios planos de Educação, a Lei 13.005/2014, que aprovou esse PNE, no Art. 8, item III exige que "[...] garantam o atendimento das necessidades específicas na educação especial, assegurado o sistema educacional inclusivo em todos os níveis, etapas e modalidades [...]". Nesse sentido, o Plano Municipal de Educação - PME/Manaus/AM (2015/2025, p. 67).

[...] aponta que a rede municipal possui em sua estrutura atualmente: 01 Escola Especial, 25 Classes Especiais, 27 Salas de Recursos Comuns ${ }^{4}, 45$ Salas de Recursos Multifuncional ${ }^{5}$ e 17 Salas 
de EJA inclusivo, atendendo 816 alunos público alvo da Educação Especial na Rede de Ensino no ano de 2014 (MANAUS, 2014).

Ao refletir sobre esses dados, pondera-se que as iniciativas de inclusão dos educandos com deficiência nos ambientes educacionais são louváveis, mas é preciso ter a clareza de que ainda há muitas pessoas excluídas precisando ser resgatadas e trazidas de volta à vida, como recorda Lemos (2008).

Tal resgate, segundo estudos de Lemos (2008), se refere ao fato de ainda existirem no Amazonas inúmeras pessoas com deficiência fora das escolas, à margem das oportunidades e da participação das políticas públicas. Desse modo, trazer estes cidadãos de volta à vida significaria chamar à responsabilidade as escolas, os governos e a sociedade civil para, por meio da conquista dos direitos, proporcionar a cada ser humano se tornar um partícipe, autônomo, atuante no tecido social vigente e, como consequência, dono da própria história.

Importa refletir que, em 2014, Manaus possuía 27 salas de recursos organizadas pela Secretaria Municipal de Educação - SEMED/Manaus/AM. $O$ quantitativo de salas de recursos multifuncionais ainda era insuficiente para 10 atender a mais de 500 escolas da rede municipal de ensino. Desse modo, conforme dados coletados em 2016 na gerência da Educação especial da Secretaria Municipal de Educação - SEMED/Manaus/AM, foram criadas essas salas de recursos, consideradas comuns, para tentar amenizar as necessidades dos educandos com deficiência, transtornos globais do desenvolvimento e altas habilidades/superdotação matriculados.

Segundo dados disponibilizados pela Secretária Municipal de Educação de Manaus/AM para a pesquisa de Lemos (2019, p. 167), "[...] o quantitativo de salas de recursos multifuncionais, em 2019, é de 82. O total de salas de recursos organizadas pela prefeitura é de 66 salas".

Apesar de se perceber o esforço empenhado para o atendimento, observa-se uma incongruência da legislação, uma vez que exige a implantação e implementação de salas de recursos multifuncionais desde a aprovação do Decreto 6.571/2008 que dispõe sobre o atendimento educacional especializado, Decreto 7.61 1/1 1, que substitui o Decreto 6.571/2008, os Planos de Educação atuais e todas as leis subsequentes.

A exemplo do Plano Municipal de Educação - PME/Manaus/AM vigente, os outros 17 PME's pesquisados apresentam como evolução das 
políticas educacionais a oferta da Educação Inclusiva, respaldando a determinação constitucional de que todos os cidadãos brasileiros devem frequentar escolas públicas e gratuitas.

A inclusão educacional pressupõe o reconhecimento e o atendimento às diferenças individuais dos educandos, evitando que se transformem em desigualdades e barreiras para o aprendizado, como ratifica Ropoli (2010, p. 9): "A escola comum se torna inclusiva quando reconhece as diferenças dos alunos diante do processo educativo e busca a participação e o progresso de todos, adotando novas práticas pedagógicas."

É inadmissível pensar na tessitura de uma sociedade inclusiva sem uma formação epistemológica e teórico-científica, mas, acima de tudo, humanística para os educadores que possam construir uma escola acessível onde todas as pessoas terão o seu lugar e onde todos possam participar, sem exceções ou exclusões.

Apesar de todos os dilemas e movimentos contrários à implementação de uma sociedade de fato Inclusiva, aprender e ensinar para os educadores ou educandos com ou sem deficiência ainda é uma arma de ruptura e de resistência, de luta pela garantia dos direitos de todos e um grande sim à vida.

Acredita-se que aprender e ensinar precisa ser uma escolha oportunizada e garantida a todos, não assistencialista, mas fruto das lutas constantes pela emancipação humana de homens e mulheres que, por meio da Educação, descobriram que é possivvel tornar-se sujeitos da própria história quando se permitem viver com dignidade na superação de barreiras, sejam impostas por outros ou por si mesmos.

Contudo, a intencionalidade do estudo é estimular pesquisas que venham minimizar o distanciamento entre os que arregimentam as políticas públicas de Educação, as práticas educativas presentes nas escolas públicas, bem como nos demais cenários políticos, econômicos e sociais em que as pessoas com deficiência se encontram inseridas. Nessa visão, pensa-se na concepção de uma sociedade onde o fenômeno social do direito à Educação não seja privilégio somente para alguns, mas, fruto das lutas advindas da vontade popular pela constituição de relações mais democráticas, solidárias, éticas, críticas e políticas para o povo brasileiro. 


\section{Uma escola democrática frente aos desafios amazônicos}

Percebe-se ao longo da história da humanidade momentos que revelam um contexto permeado por desafios e contradições de todas as ordens. Nesse turbilhão de acontecimentos, a Educação surge no cenário da escola como um contraponto e um desafio que interpela educadores e educandos com uma questão: Será possível construir uma escola democrática no contexto amazônico com o atual modelo econômico vigente no Brasil?

Questões como essa e as respostas dos entrevistados para a pesquisa de Lemos (2019) apresentam alguns desafios instigadores, pois, como afirma Bobbio (Trad. por NOGUEIRA, 1986, p. 64): "A atitude do bom democrático é não se iludir com o melhor e não se resignar com o pior." Segundo o autor, não podemos nos contentar com as situações injustas como estão postas, devemos lutar por uma Educação emancipatória.

A partir da resposta dos entrevistados, foi possível observar lacunas e dificuldades na implementação das políticas públicas, que serão analisadas a seguir.

Tabela 2

Quadro dos desafios para implementação da Meta 4 nos 18 municípios investigados

\begin{tabular}{|c|l|c|l|}
\hline Desafios & Municípios & $\%$ & \multicolumn{1}{c|}{ Respostas } \\
\hline & $\begin{array}{l}\text { Curimatá, Sardinha, } \\
\text { Peixe-Boi, Tambaqui, } \\
\text { Pacu, Surubim, } \\
\text { Matrinxã, Aruanã, } \\
\text { Acará, Pirarucu } \\
\text { Tucunaré, Pirapitinga }\end{array}$ & 67 & $\begin{array}{l}12 \text { agentes educacionais disseram que } \\
\text { as lacunas na formação continuada e } \\
\text { específica dos professores acerca de } \\
\text { como lidar, receber e atender pessoas } \\
\text { com deficiência e a escassez de mate- } \\
\text { riais didáticos adaptados para cada } \\
\text { especificidade são desafios que influen- } \\
\text { ciam diretamente no processo de ensino } \\
\text { e aprendizagem. }\end{array}$ \\
\hline
\end{tabular}




\section{Tabela 2}

\section{Quadro dos desafios para implementação da Meta 4 nos 18 municípios investigados (continuação)}

\begin{tabular}{|c|c|c|c|}
\hline Desafios & Municípios & $\%$ & Respostas \\
\hline $3^{\circ}$ & $\begin{array}{l}\text { Aruanã, Tambaqui, } \\
\text { Pacu, Pescada, } \\
\text { Acará, Surubim e } \\
\text { Pirarucu, Pirarara }\end{array}$ & 44 & $\begin{array}{l}8 \text { agentes educacionais apontaram ques- } \\
\text { tões políticas internas como empecilho } \\
\text { para o estabelecimento e materialização } \\
\text { do acordo de cooperação técnica entre } \\
\text { as ações do município e as do estado, } \\
\text { enfatizando, muitas vezes, a ausência de } \\
\text { um apoio mais específico entre os entes } \\
\text { federados. }\end{array}$ \\
\hline $4^{\circ}$ & $\begin{array}{l}\text { Curimatá, Sardinha, } \\
\text { Peixe-Boi, Tambaqui, } \\
\text { Pacu, Surubim, } \\
\text { Matrinxã, Aruanã, } \\
\text { Acará e Pirarucu }\end{array}$ & 56 & $\begin{array}{l}10 \text { agentes educacionais explicitaram } \\
\text { a desarticulação entre a Educação e a } \\
\text { Saúde no atendimento integral à pessoa } \\
\text { com deficiência, enfatizando a relevân- } \\
\text { cia de uma equipe multiprofissional para } \\
\text { atuarem em colaboração com a escola } \\
\text { no atendimento dos educandos PAEE. }\end{array}$ \\
\hline $5^{\circ}$ & $\begin{array}{l}\text { Aruanã, Tambaqui, } \\
\text { Pacu, Pescada, } \\
\text { Acará, Surubim e } \\
\text { Pirarucu }\end{array}$ & 39 & $\begin{array}{l}7 \text { agentes educacionais enfatizaram a } \\
\text { ausência da devida acessibilidade como } \\
\text { um fator relevante para a não participa- } \\
\text { ção dos educandos com deficiência nos } \\
\text { ambientes escolares, questão agravada } \\
\text { pelas distâncias territoriais e geográficas, } \\
\text { ausência de transportes fluviais acessíveis } \\
\text { e as disparidades sociais ocasionadas } \\
\text { por carências de todas as ordens. }\end{array}$ \\
\hline $6^{\circ}$ & $\begin{array}{l}\text { Dourado, Pescada, } \\
\text { Tambuatá, Pacu, } \\
\text { Peixe-Boi, Bodó, } \\
\text { Aruanã, e Jaraqui }\end{array}$ & 56 & $\begin{array}{l}8 \text { agentes educacionais explicaram } \\
\text { que a ausência, rejeição, negação da } \\
\text { condição de deficiência dos filhos ou } \\
\text { superproteção das famílias vêm se confi- } \\
\text { gurando como um desafio preponderante } \\
\text { para o desenvolvimento integral desses } \\
\text { estudantes tanto no âmbito educacional } \\
\text { quanto na inserção social. }\end{array}$ \\
\hline
\end{tabular}

Quadro elaborado por Lemos (2019).

Os seis desafios apresentados pelos agentes educacionais entrevistados nos municípios trazem dados irrefutáveis sobre alguns fatores que podem 
impedir a devida implementação da meta 4 do Plano Nacional de Educação - PNE (2014/2024). Fatores que, em menor ou maior grau, ainda segregam, alijam, marginalizam e afastam o segmento das pessoas com deficiência das escolas públicas no estado do Amazonas.

Analisando cada fator apresentado pelos agentes educacionais, avalia-se que, em relação ao $1^{\circ}$ desafio, que apresenta entraves à formação docente, um professor só pode ensinar o que aprendeu a conhecer. Desse modo, incluir o outro perpassa pela dimensão humana e requer uma formação inicial e continuada para que o educador obtenha a possibilidade de adquirir os elementos necessários ao autoconhecimento.

Lemos e Matos (2017) rememoram que a estratégia $4.3^{6}$ do Plano Estadual de Educação do Amazonas (2015/2025), na tentativa de cumprir o que prevê o Plano Nacional de Educação (2014/2024), aponta que:

[...] a Educação do Amazonas apresenta um grande desafio não apenas na oferta de formação, informação e transformação da concepção dos professores a respeito da inclusão educacional, mas, no enfrentamento das dificuldades de acesso a maior parte dos municípios do nosso Estado. (LEMOS; MATOS, 2017, p. 163).

Conforme o pensamento das autoras, uma das grandes preocupações reside no que se refere à oferta de Educação Inclusiva nas escolas mais afastadas das sedes dos municípios.

Esta realidade é observada em outras escolas amazônidas como apresenta a pesquisa de Oliveira (2018), quando revela que:

[...] nas áreas urbanas ainda há um número significativo de escolas sem Salas de Recursos Multifuncionais e na área rural, nos dois municípios pesquisados, não foram encontradas nem salas nem a oferta de Atendimento Educacional Especializado. Isto significa que a política de Atendimento Educacional Especializado, por meio das Salas de Recursos Multifuncionais, não atende ao contexto das escolas públicas da Amazônia Paraense, e em especial, às escolas do campo (OLIVEIRA, 2018, p. 35). 
Observando por esse prisma, a formação continuada docente não deve acontecer sem uma imersão profunda no contexto das realidades das quais os educadores fazem parte integrante.

No que se refere ao $2^{\circ}$ desafio, o Programa Escola Acessível, Programa de Dinheiro Direto na Escola-PDDE, subsídios, fascículos, livros, revistas e coletâneas para download gratuito, entre outras literaturas disponibilizadas no site oficial do Ministério da Educação ${ }^{7}$, podem minimizar a escassez de materiais didáticos adaptados para atender adequadamente a cada especificidade dos municípios.

Nesse sentido, o coordenador da Secretaria de Estado de Educação e Desporto - SEDUC/AM do município de Peixe-Boi lembra que "[...] talvez, se os gestores das escolas municipais e estaduais se informassem melhor, poderiam fazer grandes parcerias para o município, quando se trata dos materiais didáticos, por exemplo".

No $3^{\circ}$ desafio, percebe-se rupturas e continuidades, tensões e disputas políticas acirradas, prejudicando, muitas vezes, um bom projeto somente por ter sido idealizado pelo grupo políitico que estava no poder anteriormente, influenciando negativamente o cumprimento do Plano Municipal de Educação - PME que, por ser decenal, geralmente perpassa dois mandatos governamentais.

No que diz respeito às disputas políticas entre os entes federados que interferem nas ações educativas, o coordenador da Secretaria de Estado de Educação e Desporto - SEDUC/AM do município de Pacu afirmou:

Tem que acontecer a cooperação técnica sim. Se chega um aluno com síndrome de Down, por exemplo, e nós não o atendemos só porque ele é da Secretaria Municipal, isso para mim não é Educação (LEMOS, 2019, p. 130).

Importa registrar que, no campo educacional, o principal foco das políticas ou ações educativas deve ser o educando e não os interesses político-partidários de grupos que não se preocupam com o bem-estar da população, principalmente, nas localidades mais afastadas das grandes cidades.

No tocante ao $4^{\circ}$ desafio, observa-se a ausência de articulação entre a Educação e a Saúde nos municípios pesquisados. Ressalta-se uma carência demasiada de serviços básicos que possam oferecer às populações os 
cuidados preventivos e a devida informação acerca de muitas doenças evitáveis como as endêmicas, comuns nesta região.

Em relação à saúde dos estudantes com deficiência, Transtornos Globais do Desenvolvimento - TGD e altas habilidades/superdotação, a grande preocupação dos municípios é em torno da aquisição do laudo médico, como se pode verificar em Pescada, Dourado, Acará, Tambaqui, entre outros. Ao serem interpelados sobre o porquê dessa preocupação, os agentes educacionais alegaram que o conhecimento da deficiência poderia auxiliar os professores entenderem a metodologia adotada e, por outro lado, o censo escolar exige o laudo para a matrícula desse público alvo. Praia (2019) informou que:

As matrículas pelo SIGEAM seguem o que regulamenta a Nota Técnica n 4 (2014). Os dados que são enviados para o Censo Escolar são os da matrícula informada no início do ano letivo. No ato da matrícula, ao ser informado que aquela criança tem deficiência abre-se uma outra janela no sistema para informar o tipo de deficiência e os recursos que ela necessita utilizar. Em nenhum momento exige-se o Laudo médico. Informação verbal8 (PRAIA, 2019, p. 130-1311.

A explicação indica que não há uma exigência da apresentação de documentação comprobatória (laudo médico ou equivalente) para o cadastro das crianças com deficiência no censo escolar. No entanto, o coordenador da Secretaria de Estado de Educação e Desporto - SEDUC em Pacu, disse:

Não é uma exigência a entrega do Laudo Médico. Todavia, se eu preciso de um auxiliar de vida escolar - AVE para atender um autista, por exemplo, só consigo se comprovar (via Laudo) que ele necessita desse atendimento (LEMOS, 2019, p. 131).

Desse modo, compreende-se que a existência do laudo médico ainda é um indicativo ou justificativa para matricular ou não crianças com deficiência no ensino público, condição arbitrária que apenas demonstra que tal medida continua presente no sistema educacional do Amazonas.

A intencionalidade das políticas educacionais, segundo a concepção de Cury (2002), Mészarós (2005) e Matos (2014), deveria ser a de não atender preferencialmente a alguns em detrimento de outros, mas criar as 
oportunidades educacionais que fossem ofertadas a todos, filhos de trabalhadores ou não, sem qualquer restrição ou discriminação perante à lei.

Como afirmam Mészarós (2005), Gadotti (2006), Cury (2014) Lemos e Matos (In: MATOS, 2017), não há como pensar a transformação da escola dissociada da realidade e do marco regulatório engendrado pelas elites dominantes na produção e reprodução das desigualdades sociais. Os autores concordam que somente mudanças estruturais profundas podem originar uma escola democrática, justa e solidária, onde todos possam participar com igualdade de direitos.

Desse modo, em uma escola emancipatória e inclusiva, ressalta Cury (2014, p. 66), " [.... o o cidadão torna-se capaz de se apossar de padrões cognitivos e formativos pelos quais tem maiores possibilidades de participar dos destinos de sua sociedade e colaborar na sua transformação [... $]^{\prime \prime}$.

No $5^{\circ}$ desafio, paira a ideia de que uma adequada mobilidade urbana, incluindo a acessibilidade arquitetônica, só beneficiaria as pessoas com deficiência. No entanto, a infraestrutura acessível em uma cidade, escola ou qualquer ambiente onde haja a circulação de pessoas, também favorece senhoras com carrinhos de bebê, idosos, crianças pequenas, entre outros cidadãos, o que contemplaria o direito de ir e vir com segurança.

Nesse sentido, de acordo com o Art. 2, incisos I, II e III, da Resolução $n^{\circ} .27$, do FNDE/MEC (201 1, p. 2), que dispõe sobre o financiamento para matrículas de alunos do público alvo da Educação Especial, regulamenta que os recursos financeiros destinados às escolas públicas municipais e estaduais, por meio do Programa Escola Acessível (2013) devem ser investidos na:

I - aquisição de materiais e bens e/ou contratação de serviços para construção e adequação de rampas, alargamento de portas e passagens, instalação de corrimão, construção e adequação de sanitários para acessibilidade e colocação de sinalização visual, tátil e sonora;

II - aquisição de cadeiras de rodas, bebedouros e mobiliário acessíveis; e

III - aquisição de recursos de tecnologia assistiva ; [...] (BRASIL, 20111. 
Nesse contexto, importa destacar as dificuldades dos municípios que enfrentam seis meses de enchentes, o que inviabiliza qualquer alternativa de acessibilidade, pois, quase todas as cidades ficam submersas.

Quando ocorrem falhas estruturais em relação à acessibilidade na comunicação didático-pedagógica e atitudinal, os educadores se apercebem que incluir não é somente permitir que o educando com deficiência seja matriculado na escola, mas também as condições de aceitação, respeito às singularidades no aprendizado e mudanças das atitudes discriminatórias.

Assim, conclui Souza (2017, p. 84), no "[...] contexto escolar, todo aluno deve ter garantido a possibilidade de acesso de forma segura e independente aos espaços escolares". Esse acesso considera tanto espaços físicos quanto sociais em relação às interações com o meio ambiente.

Como apresenta $\circ 6^{\circ}$ desafio, a primeira sociedade com a qual a criança com deficiência convive é a família. É notório que, na maioria dos municípios do Amazonas, muitas famílias ainda não têm acesso às informações necessárias sobre os direitos que possuem, possivelmente, devido à herança cultural. Por considerar que uma criança com deficiência não é capaz de aprender, muitas famílias preferem deixá-la na segurança do lar ou mantida nas instituições público-privadas, sem permitir a matrícula dos filhos na escola pública convencional.

Cury (2013) rememora que o Decreto 6.571/2008, que dispõe sobre o Atendimento Educacional Especializado, regulamenta ○ Art. 60 da Lei de Diretrizes e Bases da Educação Nacional - LDBEN 9.394/1996. Nesse decreto, a União explicita a prestação de apoio técnico e financeiro aos entes federados para o atendimento especializado às pessoas com deficiência matriculadas nos estabelecimentos escolares.

A esse respeito, alguns representantes educacionais entrevistados de municípios, como Surubim, Aruanã e Jaraqui, relataram que a ausência dos investimentos financeiros destinados à Educação e que, por consequência, deveriam ser aplicados na Educação Inclusiva ameaça e precariza o atendimento mais específico aos educandos, Público Alvo da Educação Especial - PAEE. Os agentes educacionais desabafaram, dizendo que tais iniciativas por inclusão não passarão de declarações falaciosas enquanto não houver investimentos reais nessa área. 
De acordo com a Lei de Diretrizes e Bases da Educação Nacional - LDBEN vigente no país, o AEE deve tanto integrar a proposta pedagógica quanto se articular com as famílias no âmbito das políiticas públicas.

Vale salientar que um dos pressupostos norteadores para que se estabeleça uma Educação Inclusiva é que a sociedade precisa se adaptar com recursos, serviços, projetos e programas para atender às necessidades do educando e não o processo inverso, conhecido como integração escolar, temática já abordada ao longo dos tempos.

Contudo, urge perceber que o maior desafio não reside apenas em ofertar as matrículas, mas, sim, no compromisso governamental assumido para promover as condições apropriadas de permanência com sucesso e que deem oportunidade a todos os educandos com deficiência, TGD e altas habilidades/superdotação participar com autonomia e independência dos processos educacionais.

Participar, nesse viés, significa estudar em igualdade de condições com inclusão em um processo complexo, diverso, dinâmico e dialético que é aprender em meio às diferenças.

Assim, compreende-se que a escola não se tornará um espaço para todos enquanto não assumir um compromisso responsável com cada comunidade escolar na criação de ambientes acessíveis e acolhedores, gestando uma formação continuada que transforme a vida e a convivência entre educandos e educadores de todas as cores, credos, ritmos e tempos de aprendizagem.

Faz-se necessário pensar em uma escola onde as famílias possam contribuir, sem discriminação, com seus costumes e saberes populares, para que se tornem conscientes do papel educativo que possuem na vida dos filhos e para que estes construam as próprias identidades dos homens que desejam ser.

O engajamento entre escolas, famílias e sociedade fomentará mecanismos de ajustamentos de conduta para que o poder público, à luz de uma gestão democrática, cumpra e implemente o que prevê a legislação brasileira, permitindo que as políticas educacionais possam chegar nos locais mais carentes e esquecidos dessa distante e contrastante Amazônia. 


\section{Conclusões}

A investigação permitiu algumas conclusões provisórias a partir da análise de 6 desafios para tornar a escola pública mais democrática, participativa, emancipatória e inclusiva no cenário amazônico.

Embora o poder público (dono dos meios de produção) se recuse a enxergar as necessidades do segmento das pessoas com deficiência, estas não são invisíveis e, reunidas em movimentos sociais cada vez mais organizados, continuam lançando ao mundo o desafio de serem simplesmente diferentes.

Pessoas com deficiência apresentam ao mundo o desafio e a necessidade de estudarem em uma escola com formação continuada de professores, materiais adaptados e acessibilidade nos mais diversos níveis para que a lei não se transforme em letra morta. Afinal, as leis existem para serem implantadas, implementadas, fiscalizadas, monitoradas e avaliadas constantemente.

Pessoas com deficiência também lançam ao mundo o desafio de acesso ao direito de estudarem em uma escola na qual nem os acirramentos políticos, entre os entes federados, nem a desarticulação entre Saúde e Educação sejam entraves para o desenvolvimento humano de novos cidadãos.

Nesse sentido, observou-se que encontrar estratégias para valorizar os conhecimentos advindos do convívio familiar poderia dirimir as enormes distâncias entre as famílias e os ambientes educacionais. Assim, percebeu-se que possíveis conflitos podem ser sanados somente a partir do estabelecimento de novas relações, oferecendo espaço ao diálogo em prol da aprendizagem de todos os educandos.

resultado desta pesquisa é uma contribuição para motivar o respeito às diferenças, a exemplo da diversidade amazônica que não cansa de ensinar que a natureza global pode e necessita viver em harmonia ao preservar todas as espécies, dentre elas a humana.

Irmanados com os apelos, lutas, valores e culturas dos povos ameríndios, as autoras deste artigo pensam, enfim, que educar é amar profundamente as gentes de quaisquer tipos porque são dignas de afeto e tolerância. Por isso, a luta pela dignidade e defesa dos direitos apenas se inicia quando se entende que as políticas públicas devem atender todos, principalmente aqueles que ainda não aprenderam que no mundo há lugar para todos, independentemente 
da cor de pele, credo, crenças, raça, etnia, opções, escolhas ou condição física.

\section{Notas}

1 Título da tese para aprovação no Comitê de Ética em pesquisa. Por sugestão da banca de defesa da tese, foi mudado para: A implementação da Meta 4 do Plano Nacional de Educação (2014/2024) em 18 Planos Municipais de Educação no estado do Amazonas.

2 As calhas são, como se conhece nessa região, os diversos caminhos por onde passam os rios. Nos portos que aportam as embarcações, pelas estradas feitas de rios, chegam todos os produtos que abastecem a maioria dos municípios do estado.

3 PcD é uma abreviatura para pessoas com deficiência.

4 Salas de recursos consideradas comuns no município de Manaus-AM. São espaços organizados pela Secretaria Municipal de Educação - SEMED-AM, com recursos financeiros próprios e materiais didáticos adaptados pela professora da sala de recursos com o objetivo de atender crianças com deficiência, TGD e altas habilidades/superdotação.

5 Salas de recursos multifuncionais são espaços específicos cedidos pela escola para implantação de serviços, instrumentos, mobiliários e produtos com finalidades educacionais para o atendimento de crianças com deficiência, transtornos globais do desenvolvimento e altas habilidades/ superdotação, ofertadas e implementadas pelo MEC, conforme dados do Decreto 6571/2008.

6 Implantar e implementar, na vigência deste PEE, salas de recursos multifuncionais em $100 \%$ dos municípios do estado, contemplando escolas urbanas, do campo, indígenas e de comunidades quilombolas, garantindo a formação específica aos professores para atuação no atendimento educacional especializado.

7 Informações disponíveis em: www.mec.gov.br.

8 Informações fornecidas pelo coordenador do SIGEAM, Sr. PRAIA, no município de Pacu. SIGEAM, Disponível em: <https://servicos.sigeam.am.gov.br/login/login.asp. Acesso em: 6 nov. 2019.

9 Conforme o parágrafo único do Art. 2 da Resolução n. 27, do FNDE/MEC (201 1, p. 3): "Por tecnologia assistiva compreendem-se os produtos, recursos, metodologias, estratégias, práticas e serviços que objetivam promover a funcionalidade, relacionada à atividade e participação de pessoas com deficiência ou mobilidade reduzida, visando sua autonomia, independência e inclusão educacional." 


\section{Referências}

AMAZONAS. Plano Estadual de Educação/PEE/AM (2015/2025). Documento base do plano estadual de educação do Amazonas - Governo do Estado do Amazonas. Gabinete do Governador, Manaus, abr. de 2015.

BALL, Stephen John. MAINARDES, Jefferson (org.). Políticas educacionais: questões e dilemas. São Paulo: Cortez, 2011.

BATISTA, Claudenilson Pereira. Política pública de inclusão: atendimento de educandos com deficiência visual no município de Manaus/AM. 2015. 11 8f. Dissertação /Mestrado em Educação) - Programa de Pós-Graduação em Educação, Universidade Federal do Amazonas, Manaus, 2015.

$\mathrm{BOBBIO}$, Norberto. O futuro da democracia: uma defesa das regras do jogo. tradução Marco Aurélio Nogueira. Rio de Janeiro: Paz e Terra, 1986.

BRASIL. Lei n. ${ }^{\circ}$ 9.394, de $\mathbf{2 0}$ de dezembro de 1996. Lei de Diretrizes e Bases da Educação Nacional, Direito à Educação: subsídios para a gestão dos sistemas educacionais. Presidência da República. Brasília: MEC/Seesp, 2004.

BRASIL. Lei $\mathbf{n}^{\circ}$ 12.796, de $\mathbf{4}$ de abril de 2013. Altera a Lei $n^{\circ}$ 9.394, de 20 de dezem-

22 bro de 1996, que estabelece as diretrizes e bases da educação nacional, para dispor sobre a formação dos profissionais da educação e dar outras providências. Presidência da República, Brasília, 2014. Disponível em: http://www.planalto.gov.br/ccivil_03/ ato20112014/2011/decreto/d7611.htm. Acesso em: 14 jan. 2019.

BRASIL. PNE/Plano Nacional de Educação (2014/2024): Lei n 13.005, de 25 de junho de 2014, que aprova o Plano Nacional de Educação (PNE) e dá outras providências. Brasília: Câmara dos Deputados/Edições Câmara, 2014. (Atualizada em $1^{\circ}$ dez. 2014).

BRASIL. Decreto 6.571, de 17 de setembro de 2008. Dispõe sobre o atendimento educacional especializado, regulamenta o parágrafo único do art. 60 da Lei no 9.394, de 20 de dezembro de 1996, e acrescenta dispositivo ao Decreto n 6.253, de 13 de novembro de 2007. Diário Oficial da União, Brasília, Seção 1, n 181, 18 set. 2008.

BRASIL. Decreto N $\mathbf{N}^{\circ} .611$, de 17 de novembro de 2011. Dispõe sobre a educação especial, o atendimento educacional especializado, revogando o Decreto 6571/2008 e dá outras providências. Diário Oficial da União. Disponível em: http://www. planalto.gov.br/ ccivil_03/_ato2011-2014/2011/decreto/d7611.htm. Acesso em: 14 jan. 2016.

BRASIL. Instituto Brasileiro de Geografia. Estatística Empresas e outras organizações perdem 1,7 milhão de ocupados entre 2014 e 2015. Disponível em: http:/ / saladeimprensa. ibge.gov.br.comunica@ibge.gov.br. Acesso em: 10 jan. 2019. 
BRASIL. Instituto Brasileiro de Geografia e Estatística. A taxa de desemprego no Brasil ficou em 11,6\% no trimestre encerrado. IBGE, 2018, 31 jan. 2019. Disponível em: http:// saladeimprensa.ibge.gov.br.comunica@ibge.gov.br. Acesso em: 3 abr. 2019.

BRASIL. Ministério da Educação. Programa Escola Acessível/2013. Promove condições de acessibilidade ao ambiente físico, aos recursos didáticos e pedagógicos e à comunicação e informação nas escolas públicas de ensino regular. Brasília/SECADI/2013. Disponível em: http://portal.mec.gov.br/expansao-da-rede-federal/194-secretarias-1 12877938 / secad-educacao-continuada-22336954 1/17428-programa-escola-acessivel-novo. Acesso em: 10 maio 2019 .

BRASIL. Ministério da Educação. Resolução FNDE/MEC $\mathbf{n}^{\circ}$ 27, de 19 de abril de 2011. Dispõe sobre a destinação de recursos financeiros, nos moldes e sob a égide da Resolução $n^{\circ} 17$, de 19 de abril de 2011 , a escolas públicas municipais, estaduais e do Distrito Federal da educação básica, com matrículas de alunos público alvo da educação especial em classes comuns do ensino regular, que tenham sido contempladas com salas de recursos multifuncionais em 2009 e integrarão o Programa Escola Acessível em 2011. Brasília: Ministério da Educação, 2011.

CARVAlHO, Rosita Edler. Educação inclusiva: Com os pingos nos "is". 4. ed. Porto Alegre: Mediação, 2004

COSTA, Lúcia Cortes da. Os impasses do estado capitalista: uma análise sobre a reforma do Estado no Brasil. São Paulo: Cortez, 2006.

CURY, Carlos Roberto Jamil. Direito á educação: direito á igualdade, direito á diferença. Cadernos de Pesquisa, São Paulo, n. 116 , p. 245-262, jul. 2002. Disponível em:http:// www.scielo.br/scielo.php?script=sci_arttext\&pid=S0100. Acesso em: 14 abr. 2020.

CURY, Carlos Roberto Jamil. Da educação especial. In: MELETTI, Silvia Márcia Ferreira; BUENO, José Geraldo Silveira (org.) Políticas públicas, escolarização de alunos com deficiência e a pesquisa educacional. Araraquara: Junqueira \& Marin, 2013.

CURY, Carlos Roberto Jamil. Educação e direito à educação no Brasil: um histórico pelas Constituições. Belo Horizonte: Mazza Edições, 2014.

GADOTTI, Moacir; ROMÃO José Eustáquio (org.). Autonomia da escola: princípios e propostas. 6. ed. São Paulo: Cortez, 2004.

GADOTTI, Moacir. Concepção dialética da educação: um estudo introdutório. 15. ed. São Paulo: Cortez, 2006.

GUARESCHI, Pedrinho Arcides. Sociologia crítica: alternativas de mudança. 54. ed. Porto Alegre: EDIPUCRS, 2003. 
HOFLING, Eloisa de Mattos. Estado e políticas (públicas) sociais. Cadernos CEDES, Campinas, v. 21, n. 55, nov. 2001.

LEMOS, Cátia de. A implementação da Meta 4 do Plano Nacional de Educação (2014/2024) em 18 Planos Municipais de Educação no Estado do Amazonas. 2019. 220f. Tese (Doutorado em Educação) - Programa de Pós-Graduação em Educação, Universidade Federal do Amazonas, Manaus, 2019.

LEMOS, Cátia de; MATOS, Maria Almerinda de Souza. Políticas educacionais de inclusão: os planos de educação no contexto amazônico. In: MATOS, Maria Almerinda de Souza (org.) Pesquisa em educação e inclusão: fundamentos teóricos na contextura da globalização. Manaus: EDUA, 2017.

LEMOS, Cátia de. Formação e práxis do professor cego ou com baixa visão de Manaus. 2008. 109f. Dissertação (Mestrado em Educação) - Programa de Pós-Graduação em Educação, Universidade Federal do Amazonas, Manaus, 2008.

MANAUS - PME/Manaus/AM (2015/2025). Plano Municipal de Educação - Lei n 2.000 de 24 de junho de 2015. Aprova o Plano Municipal de Educação do município de Manaus e dá outras providências. Diário Oficial do município de Manaus de 24/6/2015. v. 16, n. 3.674. Disponível em: http://dom.manaus.am.gov.br/pdf/2015/junho/ DOM\%203674\%2024.06.2015\%20CAD\%201.pdf/at_download/file. Acesso em: 14 24 fev. 2020.

MATOS, Maria Almerinda de Souza (org.) Educação e política: o enfoque da diversidade, diferença e deficiência na Amazônia. Manaus: Editora Vitória. 2014.

MELETTI, Silvia Márcia Ferreira. BUENO, José Geraldo Silveira (org.). Políticas públicas, escolarização de alunos com deficiência e a pesquisa Educacional. Araraquara: Junqueira \& Marin, 2013.

MÉSZARÓS, István. Educação para além do capital. São Paulo: BoiTempo, 2005.

OLIVEIRA, Ivanilde Apoluceno de. A educação Inclusiva em escolas públicas de diferentes contextos da Amazônia Paraense. In: MANZINI, Eduardo José; OLIVEIRA, Jáima Pinheiro de; GERMANO, Giseli Donadon (org.). Política de e para educação especial. Marília: ABPEE, 2018.

PAGLIUCA, Lorita Marlena Freitag; MARIANO, Monaliza Ribeiro; OLIVEIRA, Paula Marciana Pinheiro de; OLIVEIRA, Mariana Gonçalves de; FRANCCA, Inacia Satiro Xavier de; ALMEIDA, Paulo Cesar de. Repercussão de políticas públicas inclusivas segundo análise das pessoas com deficiência. Escola Anna Nery Revista de Enfermagem, Rio de Janeiro, v. 19, n. 3, p. 493-504, jul./set. 2015. Disponível em: https://www.scielo.br/pdf/ean/v19n3/14148145-ean-19-03-0498.pdf. Acesso em: 4 ago. 2020. 
PRAIA, Gilson. Município de Pacu (Informação verbais) Sistema Integrado de Gestão Escolar do Amazonas - SIGEAM. Disponível em: https://servicos.sigeam.am.gov.br/ login/login.asp. Acesso em: 6 nov. 2019.

ROPOLl, Edilene Aparecida. A educação especial na perspectiva da inclusão escolar: a escola comum inclusiva. Brasília: Ministério da Educação, Secretaria de Educação Especial/Fortaleza: Universidade Federal do Ceará, 2010.

SÁNCHEZ, Silvio Gamboa. Epistemologia da pesquisa em educação. Campinas: Praxis, 1998

SAVIANI, Dermeval. Pesquisador, professor e educador. Belo Horizonte: Autêntica Editora, 2011.

SOUSA JÚNIOR, Justino de. Marx e a crítica da educação: da expansão liberal-democrática à crise progressivo-destrutiva do capital. Aparecida (São Paulo: Ideia \& Letras, 2010.

SOUZA, Danilo Batista de. Acessibilidade e inclusão de alunos com deficiência e/ou mobilidade reduzida na escola pública. 2017, 128f. Dissertação (Mestrado em Educação) - Programa de Pós-Graduação em Educação, Universidade Federal do Amazonas, Manaus, 2017.

TAVARES, Tais Moura; SOUZA, Ângelo Ricardo de. A política educacional como ferramenta para o direito à educação: uma leitura das demandas por educação e as propostas do Plano Nacional de Educação. In: MELETTI, Silvia Márcia Ferreira; BUENO, José Geraldo Silveira (org.). Políticas públicas, escolarização de alunos com deficiência e a pesquisa educacional. Araraquara: Junqueira \& Marin, 2013.

VIEIRA, Evaldo. A política e as bases do direito educacional. Cadernos CEDES, Campinas, v. 21, n. 55 . nov. 2001.

Profa. Dra. Cátia de Lemos

Secretaria Municipal de Educação (Manaus/Amazonas - Brasil)

Associação dos Deficientes Visuais do Amazonas (ADVAM) Pesquisadora do CNPq no Núcleo de Estudos e Pesquisas em Psicopedagogia Diferencial (NEPPD/FACED/UFAM)

Linha de Pesquisa Políticas Públicas e Desenvolvimento Regional Orcid id: https: / / orcid.org/0000-0003-0714-9900 E-mail: catia_lemos77@hotmail.com 
Artigo

Profa. Dra. Maria Almerinda de Souza Matos Programa de Pós-graduação em Educação (Manaus - Brasil) Coordenadora do Núcleo de Estudos e Pesquisas em Psicopedagogia Diferencial (NEPPD/FACED/UFAM)

Linha de Pesquisa Políticas Públicas e Desenvolvimento Regional Orcid id: https: / / orcid.org/0000-0002-4776-2155 E-mail: profalmerinda@hotmail.com

Recebido 10 jun. 2020 Aceito 4 ago. 2020 